\title{
Personalized Medicine: New Perspectives in Cancer Treatments
}

\section{Meral Güzey1,2}

${ }^{1}$ University of Maryland University College-Europe, Heidelberg, Germany

${ }^{2}$ Harvard Medical School, Boston, MA, USA

Prostate cancer is the most common non-cutaneous cancer in men $[1,2]$. PSA as a prostate cancer biomarker has served many years for the initial screening for prostate cancer. Later, there have been sincere efforts to complement this diagnostic test due to its misleading increased level for the indication of other diagnosis rather than PCa, such as BPH or inflammation [3-5]. We propose using particle swarm optimization heuristic technique, and a novel occurrence listing technique, to revise existing, available and possibly a novel biomarker. We aim to keep lists of the sequence elements, which offers criteria's to evaluate randomly generated population of sequences to evaluate the solutions [6].

Our previous studies on VDR and apoptotic gene interactions highlighted the importance of VDR for prostate cancer field [7-10]. This brought novel perspective to the personal genomic research in cancer by considering combinational studies with natural compounds for novel therapies. My observation was differences in patient portfolio needed careful examination before application of the regimens. The importance of Vitamin D to the prostate cancer is impossible to ignore since ample amount of VDR is detected in prostate tissue [11-13].

Later, we showed that cDNA microarray data from human primary prostate cell lines provided important information on potential prostate cancer biomarkers. Our major challenge was to provide best normal control for our experiments [8]. This made me to realize the application differences between different geographical parts of the world. My question was: What might be the difference between "African American, and African men, or a male patient from Northern Europe to Middle Eastern" countries. The relationship between Vitamin D status and prostate cancer were in stronger differences between "Caucasians, Scandinavians and African-Americans". There are also compelling evidence that inadequate Vitamin D exposures are associated with an increase in cancer risk and/or tumor progression [14]. The amount needed to curtail cancer remains elusive and therefore serves as a stimulus for continued investigations [15]. My observation was that each prostate cancer patient has his own individual demand for vitamin $\mathrm{D}_{3}$. Further, this problem can also exist for any other natural compounds and/ or drugs.

Presently, despite its controversy tPSA seems like the only marker routinely used in clinics. Each new assay needs to be standardized, without increasing costs unreasonably. Combination of both blood based biomarkers such as PSA(fPSA, tPSA, ProPSA, Human Kallikrein Panel/hK2, uPA, and urine based biomarkers such as, Pca3, Tmprss2ERG, urinary DNA markers, can possibly overcome the lack of specificity of PSA test [1]. These suggested solutions are still using one gene-one test approach to molecular diagnostics. Our hope is that "sequence everything" approach can be done in a cost effective clinical cancer genomics [16]. It has been shown that sequencing not only the whole genome, but also the whole exome (the coding regions of the genome) and the whole transcriptome (the transcribed RNAs) of individual tumors in an effort to identify all potentially important anomalies including prostate cancer [17].

My report emerges that personal genetic information is the major clue to solve not only dose application in clinics but also any diagnostic applications. My wish is our landmark idea, which we have created by the interaction of software engineering and cancer genetics [18-20] can approach to massive patient groups with lower cost.

\section{Acknowledgement}

Dr. Meral Guzey acknowledges her sincere thanks to the Department of General Medicine, NIH, Bethesda, Maryland, USA (Research Supplements to Promote Re-Entry into Biomedical and Behavioral Research Careers (PA-08-191) in the years of 2009 and 2010 [20].

\section{References}

1. Hansen J, Rink M, Graefen M, Shariat S, Chun FK (2013) Assays for Prostate Cancer: Changing the Screening Paradigm? Mol Diagn Ther 17: 1-8.

2. Prensner RJ, Rubin AM, Wei TJ, Chinnaiyan MA (2012) Beyond PSA: The Next Generation of Prostate Cancer Biomarkers. Sci Transl Med 4: 127 rv3.

3. Oesterling JE (1992) Prostate Specific Antigen. Improving its ability to diagnose early prostate cancer. JAMA 267: 2236-2238.

4. Wolf AM, Wender RC, Etzioni RB, Thompson IM, D'Amico AV, et al. (2010) American Cancer Society guideline for the early detection of prostate cancer update 2010. Cancer J Clin 60: 70-98.

5. Guzey M, Getzenberg. (2003) Molecular cloning techniques for prostate cance biomarkers. Unpublished Data, Department of Urology, University Pittsburgh, Pittsburgh, PA. USA

6. Unay T, Guzey M. A Swarm Intelligence Heuristic Approach to Longest Common Subsequence Problem for Arbitrary Number of Sequences. Metabolomics 2013, 3: 2

7. Güzey M, Kitada S, Reed JC (2002) Apoptosis induction by 1alpha,25dihydroxyvitamin D3 in prostate cancer. Mol Cancer Ther 1: 667-677.

8. Güzey M, Luo J, Getzenberg R (2004) Vitamin $D_{3}$ modulated gene expression patterns in primary normal prostate and prostate cancer cells. J Cell Biochem 93: $271-285$

9. Güzey M, Takayama S, Reed JC (2000) BAGIL enhances trans-activation function of vitamin D receptor. J Biol Chem 275: 40749-40756.

10. Guzey M, Criss W, DeLuca H (1996. The effect of Vitamin D and its potent analogs combined with Retinoic Acid on tumor progression in SCLC. Hacettepe University, Ankara, Turkey. (PhD thesis)

11. Peehl DM, Skowronski RJ, Leung GK, Wong ST, Stamey TA, et al. (1994) Antiproliferative effects of 1,25-dihydroxyvitamin D3 on primary cultures of human prostatic cells. Cancer Res 54: 805-810.

12. Swami, S., Krishnan, V. A., and Feldman, D (2011) Vitamin D metabolism and action in the prostate: Implications for health and disease. Mol Cell Endocrinol 347: 61-69.

13. Gross C, Peehl MD, Feldman D (1997) Vitamin D and Prostate Cancer. In Vitamin D, Feldman D, Glorieux FH, Pike JW (Ed) (3 $3^{\text {rd }}$ edn), Academic Press, San Diego, USA 1-1128.

*Corresponding author: Meral Guzey, Department of Math and Life Sciences Main campus of University Maryland University College (UMUC), USA, E-mail: meral.guzey@faculty.umuc.edu

Received June 04, 2013; Accepted August 07, 2013; Published August 13, 2013

Citation: Güzey M (2013) Personalized Medicine: New Perspectives in Cancer Treatments. Metabolomics 3: 121. doi:10.4172/2153-0769.1000121

Copyright: @ 2013 Güzey M, et al. This is an open-access article distributed unde the terms of the Creative Commons Attribution License, which permits unrestricted use, distribution, and reproduction in any medium, provided the original author and source are credited. 
14. Aloia JF (2011) Clinical review: The 2011 Report on Dietary Reference Intake for Vitamin D: Where Do We Go From Here? J Clin Endocrinol Metab 96: $2987-$ 2996.

15. Cindy DD, Milner AJ (2011) Nutrigenomics, Vitamin D and Cancer Prevention. J Nutrigenet Nutrigenomics 4: 1-11.

16. Corless CL (2011) Personalized Cancer Diagnostics. Science 334: 1217-1218.

17. Roychowdhury S, lyer KM, Robinson RD, Lonigro JR, Wu MY, et al. (2011) Personalized oncology through integrative high-throughput sequencing: a pilot study. Sci Transl Med 3, 111ra121.
18. Unay TA, Roth F (2010) Internship Report. Department of Biological Chemistry and Molecular pharmacology, Harvard Medical School, Boston, MA. 02115, USA.

19. Guzey M, Church GC (2011) LabMeeting-1, New Research Building, Harvard Medical School, Boston, MA. 02115, USA.

20. Guzey M, Blenis J (2010) MLN51: an EJC protein in translational control. Department of Cell Biology, Harvard Medical School, Boston, MA. 02115, USA. 